Article

\title{
Analysis of the Thermal-Technical Properties of Modern Log Structures
}

\author{
Jozef Švajlenka *(1) and Mária Kozlovská
}

check for

updates

Citation: Švajlenka, J.; Kozlovská, M Analysis of the Thermal-Technical Properties of Modern Log Structures. Sustainability 2021, 13, 2994. https:// doi.org/10.3390/su13052994

Academic Editor:

Elżbieta Radziszewska-Zielina

Received: 16 February 2021

Accepted: 8 March 2021

Published: 9 March 2021

Publisher's Note: MDPI stays neutral with regard to jurisdictional claims in published maps and institutional affiliations.

Copyright: (c) 2021 by the authors. Licensee MDPI, Basel, Switzerland. This article is an open access article distributed under the terms and conditions of the Creative Commons Attribution (CC BY) license (https:/ / creativecommons.org/licenses/by/ $4.0 /)$.
Department of Construction Technology, Economy and Management, Faculty of Civil Engineering, Technical University of Košice, 04200 Košice, Slovakia; maria.kozlovska@tuke.sk

* Correspondence: ingsvajl@gmail.com

\begin{abstract}
Ecological buildings" and "energy-efficient buildings" are concepts which we encounter on a daily basis and which define modern trends. The purpose of their design is to create an optimal thermal microclimate by means of heat flows that form within it or enter it. A balanced combination of heat flows creates suitable conditions for thermal comfort-a factor contributing to the quality of the internal environment of buildings. This research addresses the problem of heat distribution in construction materials based on wood and their thermal-technical properties in relation to the sustainability requirements for the thermal-technical properties of constructions and buildings. The research examines the structural parts of the external walls of modern log constructions. The objective of this work is to analyse the thermal-technical properties of the structural parts of modern log wood constructions in laboratory conditions and verify them against calculated values and values declared by manufacturers. This publication is also a contribution to the current needs in terms of the sustainability and internal environment quality of constructions in general. The publication is also a contribution to the current needs in the field of heating technology in terms of sustainability and the quality of internal environments.
\end{abstract}

Keywords: wood constructions; log structure; structural parts of wood constructions; thermaltechnical properties; heat transfer coefficient; thermal resistance; laboratory conditions; sustainable building

\section{Introduction}

If wood as a construction material is assessed in terms of environmental impact and properties such as mechanical properties, aesthetic properties and thermal-technical properties [1,2], the outcome is that it is far superior to other materials. Wood has exceptional properties, such as the ability to maintain very good indoor climatic conditions in both summer and winter and the ability to release moisture into a dry environment and absorb it from a moist environment [3,4].

Currently, there are dozens of primary wood construction systems. Some are a blend of history and the latest industrial and physical expertise, making it difficult to produce a clear classification of wood constructions and determine which technology is the best [5]. Wood constructions are most commonly divided into three categories, i.e., sandwich wood constructions, solid wood constructions and Scandinavian-type wood constructions. Another classification divides wood constructions into panel wood constructions, log constructions, skeleton wood constructions, module wood constructions and layered wood constructions [6]. As this research paper presents an analysis of modern log constructions, also called Scandinavian-type wood constructions, the following section provides a brief description of their characteristics.

Scandinavian-type wood constructions or modern log constructions originated in the Nordic countries, where they represent a centuries-long tradition [7,8] (Hemström et al., 2011; Wimmers, 2017). Thanks to their popularity, they are currently spreading to other European countries. Sandwich Scandinavian-type wood constructions are almost exclusively 
saddle-roofed, with an arrangement that achieves a high housing standard on a relatively small built-up area and with interiors exhibiting high-quality workmanship $[9,10]$. These houses can be characterised as functional and understated [11]. Wooden vertical or horizontal boards with tongues and grooves, which are ventilated, are used for these houses almost universally [12]. Plasterboard elements are often fitted to the internal walls and ceilings, and so-called fix-o-pan boards, similar to chipboard, with tongues and grooves, covered in paintable and washable foil, are also used. These boards allow quick and easy installation and their use also offers benefits for the user.

Environmental impact is a highly topical and extensively discussed issue nowadays $[13,14]$, which is also immediately relevant to the construction industry. Every construction activity has, to some extent, a negative impact on the environment. As a result, natural materials such as wood are gaining in importance [15]. Continuous development of wood materials and the introduction of advanced technologies produce a wide range of wooden structural elements [16], which are increasingly common in construction. In the production of wood constructions and their wooden structural parts, it is important to design the appropriate construction composition $[17,18]$. It is also important to verify that the structural parts of wood constructions have the appropriate design by using software for calculating their thermal-technical parameters and the thermal-technical parameters of the fragments of the external coating, such as floors, walls, ceilings, etc. This software is developed according to the standards of the countries where it is used.

Calculations of the thermal-technical properties of structural parts can be performed once the properties of the given materials to be used in the construction have been determined. Another important step is to understand the conditions in which the construction and all of its structural parts and materials will be produced [19]. The type of environment to which the construction is exposed has a significant impact on its lifetime, performance and thermal-technical properties [20,21]. The thermal-technical properties of materials are not constant, as they depend on the external conditions. Parameters such as material density, moisture, temperature and many others significantly affect thermal-technical properties and change them $[22,23]$. These parameters are often overlooked in calculations of thermal-technical properties.

Based on these considerations, this work presents an analysis of the thermal-technical parameters of the structural parts of log wood constructions. The analysis was performed in laboratory conditions and by using software on the created models for subsequent comparison.

\section{Materials and Methods}

This research examined selected parts of the external walls of modern log constructions. These structures were examined in laboratory conditions using actual samples and by means of calculation models for the sake of comparison. A diffusely closed structure and a diffusely open structure were proposed as the design variants for the research. The loadbearing frame of the external wall structures consisted of prefab wooden beam elements. The first variant selected for the research was a log sandwich structure with mineral thermal insulation and a wooden facade, and the second variant was a log structure with cork insulation. The structures had comparable thickness.

\subsection{Characterisation of the First Variant}

The first variant was a log external wall structure with mineral thermal insulation. This log external wall was built from square logs with a thickness of $92 \mathrm{~mm}$ and mounted on a pre-prepared wooden installation frame placed in a climate chamber (Figures 1 and 2). The square logs were fitted together using the tongue and groove method. Vertical holes were also drilled in the square logs, where wooden rods were inserted to reinforce the joints between them. After the joining and reinforcement of the square logs, the wall was lined with vapour-permeable foil, secured to the wood with staples. The next step was to complete a vertical wooden mesh. The vertical mesh was filled with mineral wool insulation and covered with vapour-impermeable foil. The foil was secured with 
vertical square logs, which also served as a support structure for completing the wooden facade, leaving an air gap between the wall and the wooden facade of the log structure. During the process, sensors for measuring the temperature in various parts of the wall structure were also fitted. These sensors also measured the heat flows and the moisture in the exterior and the interior. The material composition of this variant was designed to be vapour-impermeable. The purpose of the closed systems (vapour-impermeable) of the structure was to prevent the transfer of moisture from the interior to the exterior using a vapour-impermeable layer. This layer is typically made from vapour-impermeable foil, with additional elements such as special glue or tape for covering the joints and for attaching the foil to the surrounding structures. The technology of diffusely closed layers requires high quality and precision in completing the external structures and all the details.

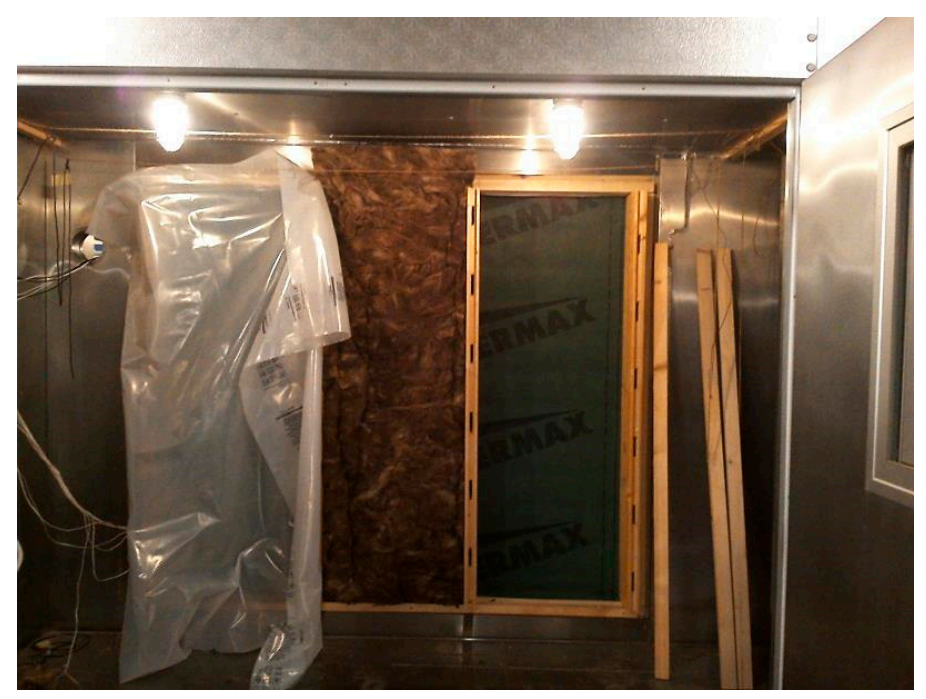

Figure 1. Realisation of construction in the climate chamber-variant 1.

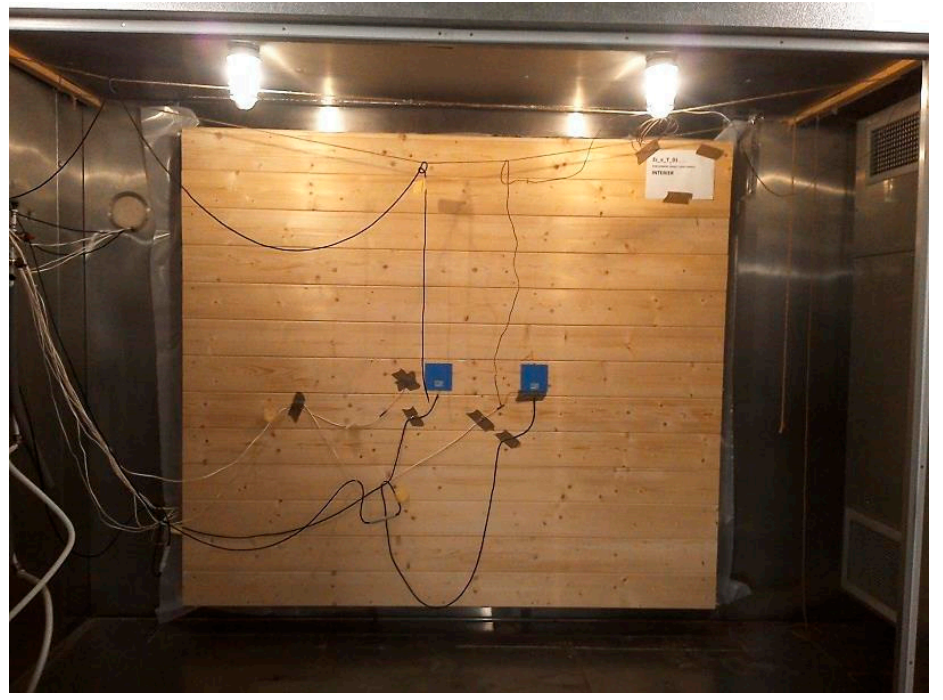

Figure 2. Analysed construction-variant 1.

\subsection{Characterisation of the Second Variant}

The second variant was a log external wall structure with cork thermal insulation. The second structure to be built was a log external wall structure with cork thermal insulation (Figures 3 and 4). The building procedure differed from the building procedure for the log external wall structure with mineral thermal insulation. Square logs with a thickness of $68 \mathrm{~mm}$ were used, but this time on both sides, joined with wooden columns. This 
wooden structure needed to be prepared before it could be fitted to the wooden installation frame in the climate chamber. After the preparation and joining of the log parts of the wall structure, the individual parts could be fitted to the wooden frame. The square logs were also fitted together using the tongue and groove method, with wooden rods inserted into drilled holes, in a way similar to the log external wall structure with mineral thermal insulation. As the pre-prepared parts were being fitted together, granulated cork was poured into the air gap to serve as thermal insulation. During the process of building the log external wall structure, sensors for measuring the temperature, heat flows and moisture were placed in the exterior and the interior. The material composition of this variant was designed to be vapour-permeable. A diffusely open (vapour-permeable) coating for wood constructions is designed so that it allows the free transfer of gases and water vapour using the mechanism of molecular transfer from the interior to the exterior. In multi-layer external coating systems for wood constructions, the individual layers must be correctly placed in the structure. The composition of these systems must contain a layer on the interior side with such diffusion resistance that will restrict water vapour diffusion to the minimum acceptable level and prevent the convection of warm moist air into the structure. Further layers in the direction towards the exterior must be arranged so that the diffusion resistance factor decreases in that direction.

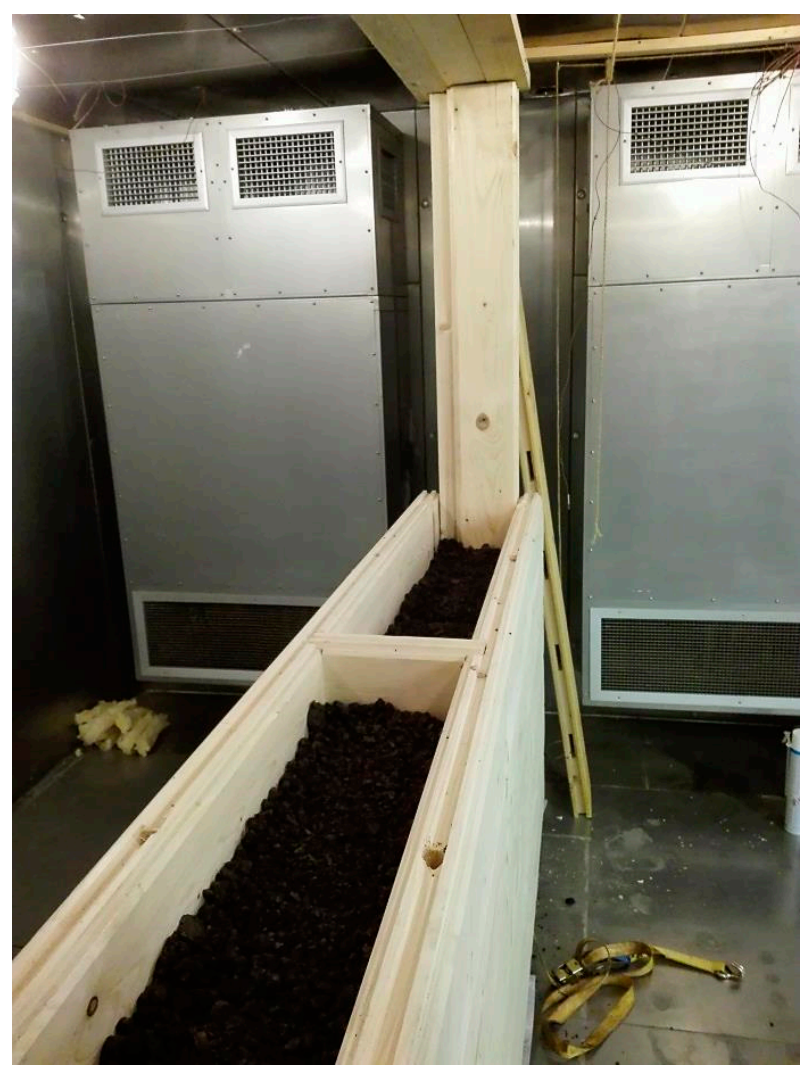

Figure 3. Realisation of construction in the climate chamber-variant 2.

Two methods were used to obtain results and the final values of the heat transfer and thermal resistance coefficients. The first method of analysis was a calculation using data from laboratory measurements and formulas for calculating the heat transfer and thermal resistance coefficients; in addition, in those cases where the thickness of the individual layers of the structures was known, also the thermal conductivity coefficients of the individual layers of the structure, their resistance during heat transfer on the inside and resistance during heat transfer on the outside were calculated. The examination of the design variants used a method of measuring the density of a heat flow passing through the structure (sample) and of measuring surface temperatures in stabilised thermal conditions, i.e., under 
virtually stable conditions. The data obtained from the experimental measurements in laboratory conditions were interpreted according to the STN 730540 standard [24]. The measurement of heat flow for the subsequent determination of selected thermal-technical parameters was also inspired by the methodologies of Evangelisti et al. [25], BienvenidoHuertas et al. [26], Kumar and Suman [27] and Meng et al. [28]. The following materialtechnical equipment was used when applying the above method of determining the $U$ value from the measured heat flow density: the ALMEMO 5690-2 (Ahlborn) measuring centre, surface temperature sensors, a plate for measuring heat flows and temperature and ambient humidity sensors. The examined design variants were placed in a climate chamber, where stable ambient conditions were simulated. The simulated temperatures were exterior and interior temperatures ranging from -13 to $20{ }^{\circ} \mathrm{C}$ [24]. The examined samples were placed in the climate chamber THERMOTRON.

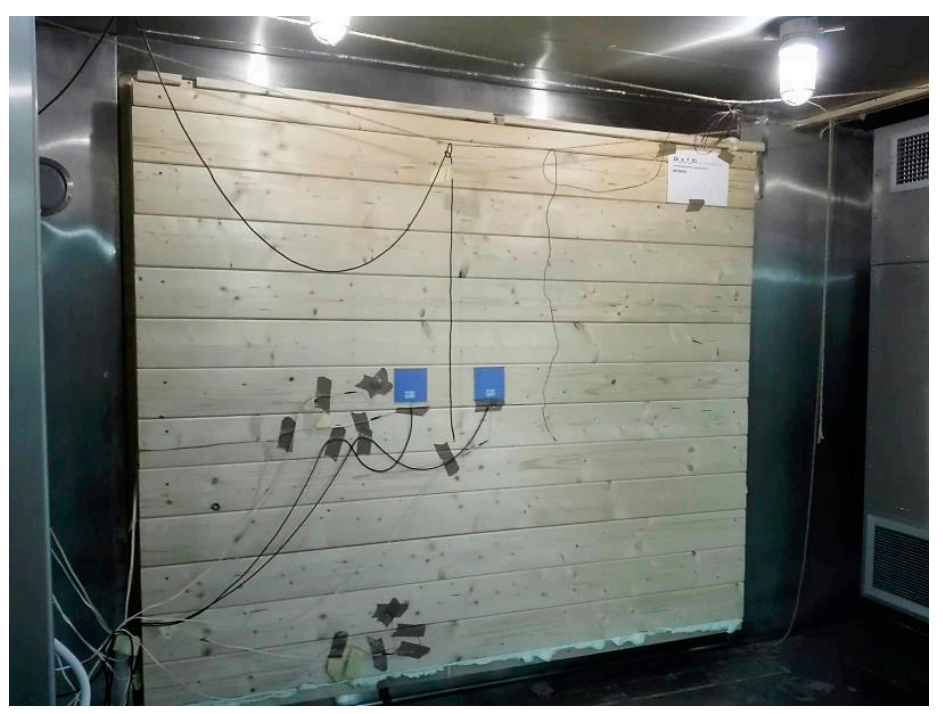

Figure 4. Analysed construction-variant 2.

The second method used software for the calculation of thermal technical characteristics of structural parts of buildings. This software analyses construction details. It is designed according to the STN-73 0540 standard [24]. If various details of a construction are modelled, the software can determine the exact indoor and outdoor temperatures, the heat transfer coefficient of non-homogeneous structures, linear heat transfer factors, the moisture values in cross-sections of structures and the water vapour condensation areas in structures. Comparable limit ambient conditions for both variants were used for calculating thermal-technical properties. The limit conditions for calculating $U$ for thermal transmittance were chosen as follows: $\mathrm{Rsi}=0.13\left(\mathrm{~m}^{2} \cdot \mathrm{K}\right) / \mathrm{W}$ a Rse $=0.04\left(\mathrm{~m}^{2} \cdot \mathrm{K}\right) / \mathrm{W}$, internal and external temperature $\mathrm{i}=20.00{ }^{\circ} \mathrm{C}$ a e $=-12.00{ }^{\circ} \mathrm{C}$, relative internal and external air humidity $\mathrm{i}=50.00 \%$ a e $=84 \%$. The choice of boundary conditions was in accordance with the valid standards for our country so that these values conflicted with the simulated laboratory boundary conditions. From this point of view, comparable boundary conditions were maintained so that the conclusions were as gentle as possible.

\section{Results}

Using instruments, measured values were obtained from the wood construction structural parts, i.e., the log external wall structure with mineral thermal insulation and the log external wall structure with cork thermal insulation. Results from each of the construction structural parts were obtained using the method of algebraic calculation performed by the software for calculating the basic thermal-technical properties of the fragments of construction coating. It was the results of the laboratory measurements and the differences between those results and the results produced by the software and the 
created models that received the most attention. As the analysed structures could not be described as homogeneous due to their special composition, it was not possible to analyse them precisely using the software, so emphasis was placed on laboratory measurements, which could more accurately reflect the actual properties of the analysed structure types.

\subsection{Analysis of the Results of Laboratory Measurements}

Measured values were obtained from the wood construction structural parts, i.e., the log external wall structure with mineral thermal insulation and the log external wall structure with cork thermal insulation, using the sensors fitted to the different parts of the structures. There were several sensors for measuring temperature, heat flows and moisture. The first sensor measured the relative air moisture of the external environment, the second sensor measured the temperature of the external environment, the third sensor measured the relative air moisture of the internal environment, the fourth sensor measured the temperature of the internal environment and the fifth sensor measured the heat flow through the structure. Before starting the measurements, it was necessary to set limit conditions such as environment temperature and air moisture in order to run simulations. External environment temperature was set to $-13^{\circ} \mathrm{C}$ and relative air moisture to $84 \%$, and internal environment temperature was set to $+20^{\circ} \mathrm{C}$ and relative air moisture to $50 \%$. These limit conditions were used for both structure types. When the limit conditions were set, the measurement cycle was launched. The measurements lasted for a period of 24 hours for each variant. The values from the individual sensors were recorded by a digital recorder at 1-minute intervals.

For the first calculation method, i.e., the method based on the measured values from the laboratory measurements of the wood construction structural parts, it was necessary to abstract valid values (values after the examined samples stabilised) from the measured values. In other words, data were abstracted from the measurements after the stabilisation of the heat flows through the structures. Temperature and heat flow values were recorded during the measurement of the values of the log external wall structures at 1-minute intervals. Figure 5 shows the heat flows and temperatures in the measured locations of the structure.

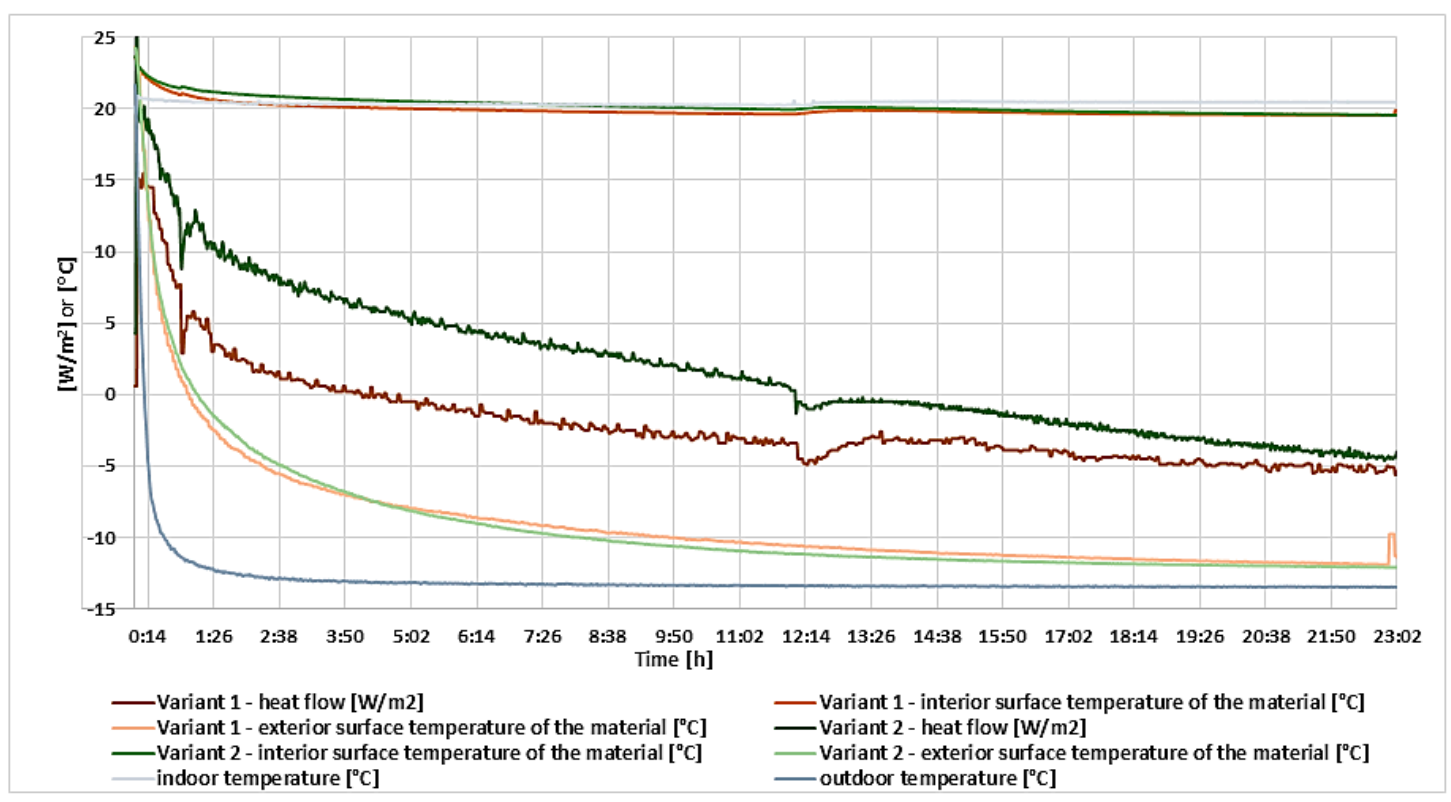

Figure 5. Temperature and heat flow values of the log structures in laboratory measurements.

The final values of the heat flow and thermal resistance coefficients were calculated and summarised by analysing the data from the laboratory measurements. The following parameters were found for variant $1: \mathrm{U}=0.17 \mathrm{~W} / \mathrm{m}^{2} \cdot \mathrm{K}, \mathrm{R}=5.88 \mathrm{~m}^{2} \cdot \mathrm{K} / \mathrm{W}$. The following 
parameters were found for variant 2 : $\mathrm{U}=0.13 \mathrm{~W} / \mathrm{m}^{2} \cdot \mathrm{K}, \mathrm{R}=7.69 \mathrm{~m}^{2} \cdot \mathrm{K} / \mathrm{W}$. The comparison in laboratory conditions showed that the structure with cork insulation, i.e., variant 2 , exhibited better thermal-technical properties than variant 1.

\subsection{Analysis of the Results from Calculation Models}

Software for calculating the thermal-technical properties of the fragments of construction coatings (wall, ceiling, floor and others), with one-dimensional heat and moisture conduction, i.e., without the effect of a thermal bridge, was used to obtain the theoretical calculation values of the heat transfer and thermal resistance coefficients. In the calculation models, the modelled structures were designed as identical copies of the structures examined in laboratory conditions.

\subsection{Log External Wall Structure with Mineral Thermal Insulation}

The thickness of the individual layers of the log external wall structure with mineral thermal insulation can also be seen in Table 1. In addition to the thickness of the structure, the table also shows values such as volumetric weight $\left(\mathrm{kg} / \mathrm{m}^{3}\right)$, thermal conductivity coefficient $(\mathrm{W} /(\mathrm{m} \cdot \mathrm{K}))$, heat capacity $(\mathrm{J} /(\mathrm{kg} \cdot \mathrm{K}))$ and diffusion resistance factor.

Table 1. Composition-log external wall structure with mineral thermal insulation.

\begin{tabular}{|c|c|c|c|c|}
\hline Layer Name & $\begin{array}{l}\text { Volumetric Weight } \\
\rho\left(\mathrm{kg} \cdot \mathrm{m}^{3}\right)\end{array}$ & $\begin{array}{l}\text { Layer Thickness } \\
\text { d (mm) }\end{array}$ & $\begin{array}{l}\text { Thermal Conductivity Coefficient } \\
\qquad \lambda_{d}(W /(m . K .))\end{array}$ & $\begin{array}{c}\text { Diffusion Resistance Factor } \\
\mu(-)\end{array}$ \\
\hline Coniferous wood & 400 & 19 & 0.13 & 157 \\
\hline Air cavity & - & 25 & 0.147 & 1 \\
\hline Vapour barrier & 140 & 0.2 & 0.21 & 160109 \\
\hline Thermal insulation & 26 & 200 & 0.034 & 1 \\
\hline Vapour-permeable foil & 1000 & 0.4 & 0.21 & 57 \\
\hline Coniferous wood & 400 & 92 & 0.13 & 157 \\
\hline
\end{tabular}

\subsection{Log External Wall Structure with Cork Thermal Insulation}

The thickness of the individual layers of the log external wall structure with cork thermal insulation can also be seen in Table 2. In addition to the thickness of the structure, the table also shows values such as volumetric weight $\left(\mathrm{kg} / \mathrm{m}^{3}\right)$, thermal conductivity coefficient $(\mathrm{W} /(\mathrm{m} \cdot \mathrm{K}))$, heat capacity $(\mathrm{J} /(\mathrm{kg} \cdot \mathrm{K}))$ and diffusion resistance factor.

Table 2. Composition-log external wall structure with cork thermal insulation.

\begin{tabular}{ccccc}
\hline Layer Name & $\begin{array}{c}\text { Volumetric Weight } \\
\boldsymbol{\rho}\left(\mathbf{k g} \cdot \mathbf{m}^{\mathbf{3}}\right)\end{array}$ & $\begin{array}{c}\text { Layer Thickness } \\
\mathbf{d}(\mathbf{m m})\end{array}$ & $\begin{array}{c}\text { Thermal Conductivity Coefficient } \\
\boldsymbol{\lambda}_{\mathbf{d}}(\mathbf{W} /(\mathbf{m} . K .))\end{array}$ & $\begin{array}{c}\text { Diffusion Resistance Factor } \\
\boldsymbol{\mu}(-)\end{array}$ \\
\hline Coniferous wood & 400 & 19 & 0.13 & 157 \\
\hline Cork thermal insulation & 45 & 220 & 0.04 & 3 \\
\hline Coniferous wood & 400 & 92 & 0.13 & 157 \\
\hline
\end{tabular}

The theoretical analysis of the simulated models using the software produced the parameters of the structures as follows: variant $1 \mathrm{U}=0.15 \mathrm{~W} / \mathrm{m}^{2} \cdot \mathrm{K}, \mathrm{R}=6.50 \mathrm{~m}^{2} \cdot \mathrm{K} / \mathrm{W}$ and variant $2 \mathrm{U}=0.16 \mathrm{~W} / \mathrm{m}^{2} \cdot \mathrm{K}, \mathrm{R}=6.04 \mathrm{~m}^{2} \cdot \mathrm{K} / \mathrm{W}$.

Certain differences between the assessed variants can be seen in the calculation models. The difference exhibited by the simulation models was not as significant as the difference exhibited by the laboratory measurements. In the simulation models, variant 1 also exhibited slightly better parameters than variant 2 . It follows from this that the log external wall structure with cork thermal insulation had better thermal-technical properties than the log external wall structure with mineral thermal insulation. However, the difference between the compared variants was negligible. 
Following the comparison of the laboratory and calculation analyses, it can be stated that the analysed structures exhibited different thermal-technical parameters in the laboratory simulations from the parameters exhibited in the calculation simulations.

As for limitations, this research may be limited by the measurements being conducted in laboratory conditions, where deviations are more likely to occur. For instance, the sensors used to measure thermal flows, surface temperatures and moisture work with a certain minimum deviation, which needs to be taken into account.

Another reason that deviations may occur in these types of measurements is that the examined structures are not homogeneous. As wood is not a homogeneous material, it is necessary to adapt the placement of the measurement points accordingly for the measurements to be valid. Before installing the measurement points, the structure must be assessed with the aim of reducing the effects on these points. In this research, the laboratory simulations were performed on a sufficiently large sample, which, for instance, eliminated side energy loss in the structure. Theoretical calculation models also have their limitations, as they rely on the ideal values of materials, which differ in certain ways from the actual in-situ conditions.

The key aspect of this study is the comparison of laboratory and computational and declared values, respectively. In this sense, the benefit of the research is mainly in terms of providing insight into how the declared parameters differ from those measured in laboratory conditions. The findings show that these values differ at certain moments and therefore it is necessary to take this into account in the future design of wood-based buildings. This work expands the knowledge in the study of the thermal-technical properties of wood-based buildings. At present, there are many construction systems for the implementation of wood-based constructions. In addition, the individual construction systems are not the same if they are manufactured and implemented by different companies. Each manufacturer adapts the technology according to their needs and the needs of their endconsumers. Therefore, it is necessary to examine the various options that are currently being implemented. This work also contributes in this sense to the knowledge in the field of wooden buildings as such.

The popularity of wood-based constructions is increasing. The popularity of this construction system stems from its advantages, particularly the ratio of weight to static loadbearing capacity. Mainly for this reason, wood-based construction systems are becoming the main alternative to the traditionally used construction system based on concrete, steel and masonry. Other advantages are the possibility to implement constructions by the socalled dry construction method and the fact that wood-based constructions have favourable environmental parameters compared to the traditional construction method [29]. Wooden buildings and wood-based construction systems behave differently at some point than traditional solutions in terms of energy diffusion in construction systems. This condition is mainly caused by the fact that wood-based constructions do not have homogeneous constructions and are often realised from so-called sandwich components. Therefore, more knowledge in this area is needed, besides that of how the individual design solutions behave in real conditions, which was also the goal of this presented research.

There is a great deal of research dealing with wooden buildings from different perspectives and with different methods of analysis. For example, the research by Tapanainen et al. [30] dealt with the combustion efficiency of log wood in the context of the production of particulate matter. These authors state that in terms of emission production during combustion, the technique and method of combustion play an important role. Thus, it is possible with these techniques to influence the mentioned adverse effects on the environment.

Falk's [31] work focused on wood from the point of view of sustainability as such and its use and application in wood-based constructions. Based on the analyses presented in this work, the conclusions state that it is clear that the green building movement is here to stay and will undoubtedly grow in the future. This could be beneficial for the wood industry, because there is a positive and convincing story to tell about wood as a sustainable and environmentally preferable material. By providing the green building community with 
science-based facts about its sustainability, embodied energy and carbon impact, wood may stand out as the greenest of building materials. However, an important aspect to mention in this work is that it is necessary to consider the origin of wood. Thus, it is important to use in construction applications such wood that is certified and comes from a sustainable forest, is processed in a sustainable way and is applied in the construction of sustainable buildings. The knowledge gained during our research in the field of wood-based construction systems agrees with these statements.

The work of Eriksson et al. [32] addressed climate change mitigation through the increased use of wood in the European construction industry-towards an integrated modelling framework. In this research, they modelled three scenarios over 23 years. Two scenarios assumed that, by 2030, another one million residential dwellings would be produced annually from wooden materials instead of non-wooden ones. These scenarios have had little impact on markets and forest management and have reduced annual carbon emissions by $0.2-0.5 \%$ of the total European Greenhouse Gas Emissions. The third scenario, the extreme assumption that all European countries will consume $1 \mathrm{~m}^{3}$ of sawn wood per capita by 2030, has had a major impact on carbon emissions, volumes and trade flows. However, price changes in this scenario also affected forest management in ways that differed significantly from the projections of the partial equilibrium model. The results of this research suggest that increased use of wood in construction applications will have little impact on forestry and carbon stocks in forests. However, ultimately, the implementation of more environmentally friendly building structures can reduce the negative impacts of the construction industry on the environment. These findings are also supported by our findings. Indeed, we state in our research that modern wood-based buildings can undoubtedly compete with traditional building systems both in terms of thermal-technical parameters and in terms of other physical and mechanical properties of buildings as such.

Similar issues have been addressed by Börjesson and Gustavsson [33] in their work on greenhouse gas residues in building construction, focusing on wood versus concrete in terms of life cycle and forest land use. In principle, this study shows that wood used in construction applications can fully compete with traditional materials. In addition, wood has many favourable environmental benefits compared to conventional materials. Based on our knowledge, we support these claims. However, it is important to note that the use of wood is not possible in all situations and applications to replace traditional materials; therefore, it is necessary to deepen knowledge about wood-based constructions and carefully consider the applications of wood in construction solutions.

Nevertheless, many works in the field of wooden buildings deal with the impact of these buildings on the environment. Proof of this is the work of the authors Diyamandoglu and Fortuna [34], where they focused on the reconstruction of houses with wooden frames in the context of material recovery and environmental impact. Among other findings, it can be abstracted from the conclusions of this work that wooden elements used in construction can be recycled in other sub-applications, provided that disassembly is possible. Thus, the reuse of certain wood-based parts also contributes to reducing the negative impact on the environment. Our knowledge is based on these statements and on our work with various wood-based applications. For example, during the implementation of our research within the construction system based on modern log elements, it was not difficult to disassemble and reassemble the structure without damaging the beams. Thus, the recycling or reuse of these elements is possible, for example, in contrast to traditional monolithic reinforced concrete structures, which, after disassembly or demolition, cannot be used in their original state. Thus, it is necessary to separate raw materials, recycle them and expend considerable energy for their reutilisation. Moreover, embodied energy in traditional conventional building solutions is incomparably higher than in wood-based applications.

The consumption of primary energy during the life cycle and the carbon footprint of conventional and passive houses with a wooden frame was addressed by the authors Dodoo and Gustavsson [35]. From the conclusions of this research, it is possible to highlight the fact that wooden buildings as such can undoubtedly achieve the strictest energy 
standards in comparison with traditional conventional building solutions. Thus, at present, when enormous emphasis is placed on the efficient use of energy in all phases of the life cycle, it is necessary to address this issue. We also support these findings on the basis of our analyses, where we found that blue wood-based construction solutions can achieve the required energy standard according to legislative requirements and also the requirements of end-users of buildings. This means that modern wooden buildings may be more interesting for future investors and developers in terms of the sustainability of their projects.

The authors Katunská and Katunský [36] offered alternative solutions of wooden external walls in their research. In this work, they analysed a similar type of construction as we do in ours, but their construction system was based on round log elements. In our research, we analysed a related system based on a traditional log construction system, but in our case, a system based on a modern design of the so-called Scandinavian type of wood-based buildings was analysed. By comparing this work with ours, we found certain parallels. However, from the conclusions of this work, it can be stated that the modern design of log construction systems provides significantly better thermal-technical parameters than the classical alternative. The main reason is that the modern solution uses the greater potential of solid wood than the classic solution and this results in the mentioned benefits in terms of thermal-technical parameters but also others.

The authors Liu et al. [37] also dealt with a similar issue as we dealt with in our research; in our work, we simulated various environmental conditions in a climate chamber, where we investigated various wood-based wall structures. However, in this work, they focused on a different principle of the design solution, in contrast to our work. In our work, we investigated design solutions of perimeter structures based on massive log elements. In their work, Liu et al. investigated construction solutions based on a sandwich construction, the supporting part of which was a frame or skeleton. As part of the interweaving of knowledge from the above research, it can be abstracted that sandwich constructions show very favourable thermal-technical parameters, which can fully compete with traditional building solutions for more subtle wall constructions. This makes it possible to make better use of the acquired internal usable space of such solutions with a low built-up area than with conventional building solutions. Our findings based on the analysis of wood-based structural systems in various variants of structural compositions also coincide with these findings.

Authors Kancelák et al. [38], in their research, also deal with the examination of selected thermal-technical parameters of log buildings. However, the construction systems analysed in their work were made of round beams, which is different from the system that we analysed in our work. A certain parallel with our research is the fact that their analysed buildings do not achieve such thermal-technical parameters as a modern log house solution based on the Scandinavian type. The authors Kecálek and Petrríček [39] also analysed traditional log construction in their research, but only through simulation models. From the conclusions of this research, it can be stated that traditional log constructions have a lower so-called effective area of the structure because the rounding reduces their thermal-technical parameters. In contrast, the constructions that we analysed in our work eliminate these shortcomings by the fact that the individual log houses are chamfered and have a higher contact surface, which is not cooled by rounding.

\section{Conclusions}

With its properties, wood meets all the requirements for modern construction materials. The main advantage of wood as a construction material is its mechanical resistance, good thermal-technical properties and environmental impact. All these properties make it suitable for use in low-energy constructions. The dominant trend in the current construction industry is reduction in energy demand and energy saving in the operation of buildings. The objective of this research was to create, model and analyse structural parts used as elements of modern log constructions in terms of selected thermal- 
technical parameters. The analysis of the two external wall structure variants using laboratory measurements showed that the log external wall structure with cork thermal insulation had better thermal-technical properties than the log external wall structure with mineral thermal insulation. This finding was also confirmed by the manual calculation from the values obtained from the laboratory measurements as well as by the software calculation. The final values of the heat transfer and thermal resistance coefficients of the wood construction's structural parts obtained using the software differed from the final values from the calculations of the laboratory measurements. The final values from the laboratory measurements (variant $1: \mathrm{U}=0.17 \mathrm{~W} / \mathrm{m}^{2} \cdot \mathrm{K}, \mathrm{R}=5.88 \mathrm{~m}^{2} \cdot \mathrm{K} / \mathrm{W}$; variant 2: $\mathrm{U}=0.13 \mathrm{~W} / \mathrm{m}^{2} \cdot \mathrm{K}, \mathrm{R}=7.69 \mathrm{~m}^{2} \cdot \mathrm{K} / \mathrm{W}$ ) were better than the final values from the software (variant $1: \mathrm{U}=0.15 \mathrm{~W} / \mathrm{m}^{2} \cdot \mathrm{K}, \mathrm{R}=6.50 \mathrm{~m}^{2} \cdot \mathrm{K} / \mathrm{W}$; variant $2: \mathrm{U}=0.16 \mathrm{~W} / \mathrm{m}^{2} \cdot \mathrm{K}$, $\left.\mathrm{R}=6.04 \mathrm{~m}^{2} \cdot \mathrm{K} / \mathrm{W}\right)$. The results of this research show that the theoretical characteristics of such types of structures differ in certain ways from the calculated ones. Another significant finding is that these types of constructions can compete with traditional constructions not only in terms of sustainability but also in terms of the thermal-technical parameters of external structures.

Author Contributions: J.Š. Conceptualization, Data curation; J.Š., M.K. Formal analysis; J.Š. Investigation; J.Š. Methodology; J.Šs. Project administration; J.Š., M.K. Resources; J.Š. Software; J.Š., M.K. Supervision; J.Š., M.K. Validation; J.Š. Visualization; J.Š. Writing—original draft; J.Š. Writing—review \& editing. All authors have read and agreed to the published version of the manuscript.

Funding: VEGA project-1/0557/18 "Research and development of the process and product innovations of modern methods of construction in the context of the Industry 4.0 principles".

Acknowledgments: VEGA project-1/0557/18 "Research and development of the process and product innovations of modern methods of construction in the context of the Industry 4.0 principles".

Conflicts of Interest: The authors declare no conflict of interest.

\section{References}

1. Hall, M.R.; Lindsay, R.; Krayenhoff, M. (Eds.) Modern Earth Buildings: Materials, Engineering, Constructions and Applications; Elsevier: Amsterdam, The Netherlands, 2012.

2. Duggal, S.K. Building Materials; Routledge: London, UK, 2017.

3. Asdrubali, F.; Ferracuti, B.; Lombardi, L.; Guattari, C.; Evangelisti, L.; Grazieschi, G. A review of structural, thermo-physical, acoustical, and environmental properties of wooden materials for building applications. Build. Environ. 2017, 114, 307-332. [CrossRef]

4. Pacheco-Torgal, F.; Cabeza, L.F.; Labrincha, J.; De Magalhaes, A.G. Eco-Efficient Construction and Building Materials: Life Cycle Assessment (LCA), Eco-Labelling and Case Studies; Woodhead Publishing: Cambridge, UK, 2014.

5. Ross, R.J. Wood Handbook: Wood as an Engineering Material; General Technical Report FPL-GTR-190; USDA Forest Service, Forest Products Laboratory: Madison, WI, USA, 2010; p. 509.

6. Menges, A.; Schwinn, T.; Krieg, O.D. (Eds.) Advancing Wood Architecture: A Computational Approach; Routledge: London, UK, 2016.

7. Hemström, K.; Mahapatra, K.; Gustavsson, L. Perceptions, attitudes and interest of Swedish architects towards the use of wood frames in multi-storey buildings. Resour. Conserv. Recycl. 2011, 55, 1013-1021. [CrossRef]

8. Wimmers, G. Wood: A construction material for tall buildings. Nat. Rev. Mater. 2017, 2, 1-2. [CrossRef]

9. Allen, E.; Iano, J. Fundamentals of Building Construction: Materials and Methods; John Wiley \& Sons: Hoboken, NJ, USA, 2019.

10. Wacker, J.P. Use of wood in buildings and bridges. In Wood Handbook: Wood as an Engineering Material; Centennial, Ed.; General Technical Report FPL-GTR-190; US Department of Agriculture, Forest Service, Forest Products Laboratory: Madison, WI, USA, 2010; Chapter 17; pp. 17.1-17.13.

11. Nilsen, A. Vernacular Buildings and Urban Social Practice: Wood and People in Early Modern Swedish Society; Archaeopress Publishing Ltd.: Oxford, UK, 2021.

12. Harte, A.M. Mass timber-the emergence of a modern construction material. J. Struct. Integr. Maint. 2017, 2, 121-132. [CrossRef]

13. Schön, C.; Hartmann, H. Log wood combustion in stoves-Influence on Emissions and efficiency. In Proceedings of the 20th European Biomass Conference \& Exhibition-From Research to Industry and Markets 2012, Milan, Italy, 18-22 June 2012; ETA Renewable Energies: Florence, Italy; pp. 1293-1298.

14. Ellingwood, B.R.; Rosowsky, D.V.; Pang, W. Performance of light-frame wood residential construction subjected to earthquakes in regions of moderate seismicity. J. Struct. Eng. 2008, 134, 1353-1363. [CrossRef]

15. Fridley, K.J. Wood and wood-based materials: Current status and future of a structural material. J. Mater. Civ. Eng. 2002, 14, 91-96. [CrossRef] 
16. Ramage, M.H.; Burridge, H.; Busse-Wicher, M.; Fereday, G.; Reynolds, T.; Shah, D.U.; Scherman, O. The wood from the trees: The use of timber in construction. Renew. Sustain. Energy Rev. 2017, 68, 333-359. [CrossRef]

17. Kalt, G. Carbon dynamics and GHG implications of increasing wood construction: Long-term scenarios for residential buildings in Austria. Carbon Manag. 2018, 9, 265-275. [CrossRef]

18. Tonooka, Y.; Takaguchi, H.; Yasui, K.; Maeda, T. Life cycle assessment of a domestic natural materials wood house. Energy Procedia 2014, 61, 1634-1637. [CrossRef]

19. Evangelisti, L.; Guattari, C.; Gori, P.; Asdrubali, F. Assessment of equivalent thermal properties of multilayer building walls coupling simulations and experimental measurements. Build. Environ. 2018, 127, 77-85. [CrossRef]

20. Svatos, J.; Holub, J. Woodhouse Energy Consumption Measurement System for Diagnostics of Thermal and Technical Properties of Buildings Envelope. In Proceedings of the 23rd IMEKO TC4 International Symposium Electrical \& Electronic Measurements Promote Industry 4.0, Xi'an, China, 17-20 September 2019.

21. Asdrubali, F.; D’Alessandro, F.; Schiavoni, S. A review of unconventional sustainable building insulation materials. Sustain. Mater. Technol. 2015, 4, 1-17. [CrossRef]

22. Khoukhi, M. The combined effect of heat and moisture transfer dependent thermal conductivity of polystyrene insulation material: Impact on building energy performance. Energy Build. 2018, 169, 228-235. [CrossRef]

23. Choe, G.; Kim, G.; Yoon, M.; Hwang, E.; Nam, J.; Guncunski, N. Effect of moisture migration and water vapor pressure build-up with the heating rate on concrete spalling type. Cem. Concr. Res. 2019, 116, 1-10. [CrossRef]

24. STN 73 0540. Thermal Performance of Buildings and Components. Thermal Protection of Buildings. 2002. Available online: https:/ / www.sutn.sk/eshop/public/standard_detail.aspx?id=128945 (accessed on 10 February 2021).

25. Meng, X.; Yan, B.; Gao, Y.; Wang, J.; Zhang, W.; Long, E. Factors affecting the in situ measurement accuracy of the wall heat transfer coefficient using the heat flow meter method. Energy Build. 2015, 86, 754-765. [CrossRef]

26. Kumar, A.; Suman, B.M. Experimental evaluation of insulation materials for walls and roofs and their impact on indoor thermal comfort under composite climate. Build. Environ. 2013, 59, 635-643. [CrossRef]

27. Evangelisti, L.; Guattari, C.; Gori, P.; Vollaro, R.D.L. In situ thermal transmittance measurements for investigating differences between wall models and actual building performance. Sustainability 2015, 7, 10388-10398. [CrossRef]

28. Bienvenido-Huertas, D.; Moyano, J.; Marín, D.; Fresco-Contreras, R. Review of in situ methods for assessing the thermal transmittance of walls. Renew. Sustain. Energy Rev. 2019, 102, 356-371. [CrossRef]

29. Brandner, R.; Flatscher, G.; Ringhofer, A.; Schickhofer, G.; Thiel, A. Cross laminated timber (CLT): Overview and development. Eur. J. Wood Wood Prod. 2016, 74, 331-351. [CrossRef]

30. Tapanainen, M.; Jalava, P.I.; Mäki-Paakkanen, J.; Hakulinen, P.; Lamberg, H.; Ruusunen, J.; Hirvonen, M.R. Efficiency of log wood combustion affects the toxicological and chemical properties of emission particles. Inhal. Toxicol. 2012, 24, 343-355. [CrossRef] [PubMed]

31. Falk, R.H. Wood as a sustainable building material. For. Prod. J. 2009, 59, 6-12.

32. Eriksson, L.O.; Gustavsson, L.; Hänninen, R.; Kallio, M.; Lyhykäinen, H.; Pingoud, K.; Valsta, L. Climate change mitigation through increased wood use in the European construction sector-towards an integrated modelling framework. Eur. J. For. Res. 2012, 131, 131-144. [CrossRef]

33. Börjesson, P.; Gustavsson, L. Greenhouse gas balances in building construction: Wood versus concrete from life-cycle and forest land-use perspectives. Energy Policy 2000, 28, 575-588. [CrossRef]

34. Diyamandoglu, V.; Fortuna, L.M. Deconstruction of wood-framed houses: Material recovery and environmental impact. Resour. Conserv. Recycl. 2015, 100, 21-30. [CrossRef]

35. Dodoo, A.; Gustavsson, L. Life cycle primary energy use and carbon footprint of wood-frame conventional and passive houses with biomass-based energy supply. Appl. Energy 2013, 112, 834-842. [CrossRef]

36. Katunská, J.; Katunský, D. Alternative Solutions of Wooden External Walls-Case Study. ABCM Advanced Building Constructions and Materials At: Lednice, Czech Republic, 2017; pp. 1-8. Available online: https://www.researchgate.net/publication/321701 063_Alternative_Solutions_of_Wooden_External_Walls-Case_Study (accessed on 10 February 2021).

37. Liu, M.; Sun, Y.; Sun, C.; Yang, X. Study on thermal insulation and heat transfer properties of wood frame walls. Wood Res. 2018, 63, 249-260.

38. Kacálek, P.; Smolka, R.; Petříček, T. Design Properties of Log Walls with Respect to Building Physics. Adv. Mater. Res. 2014, 1041, 288-292. [CrossRef]

39. Kacálek, P.; Petříček, T. The Structural Design of Wooden Solid Log Wall. In Proceedings of the 10th International Scientific Conference Building Defects (Building Defects 2018), České Budějovice, Czech Republic, 29-30 November 2018; Volume 279, p. 02015. 